\title{
Molecular Genetic Diversity and Population Structure Analysis in Chickpea (Cicer arietinum L.) Germplasm using SSR Markers
}

\author{
S.M. Samyuktha, J.R. Kannan Bapu and S. Geethanjali* \\ Centre for Plant Breeding and Genetics, Tamil Nadu Agricultural University, \\ Coimbatore- 641 003, Tamil Nadu, India \\ *Corresponding author
}

\begin{tabular}{|l|}
\hline Ke y w o r d s \\
Chickpea, SSR \\
markers, Genetic \\
diversity, \\
Population structure \\
\hline Article Info \\
\hline $\begin{array}{l}\text { Accepted: } \\
\text { 07 January } 2018 \\
\text { Available Online: } \\
\text { 10 February } 2018\end{array}$ \\
\hline
\end{tabular}

\section{Introduction}

Chickpea (Cicer arietinum L.) is a selfpollinated diploid $(2 n=16)$ grain legume with a genome size of $\Omega 740 \mathrm{Mb}$. According to Vavilov (1926), South West Asia and the Mediterranean region are the two primary centers of origin and Ethiopia is the secondary center of origin for chickpea. Chickpea is grown in more than 50 countries in the world having good wealth of alleles in the cultivated
The genetic diversity and population structure in 51 chickpea accessions were studied using 30 chickpea specific SSR markers. Twenty eight SSR markers exhibited polymorphism producing a total of 217 alleles. The average number of alleles per locus was 7.75. The average PIC value was 0.75 and ranged from a minimum of 0.53 (TA1) to a maximum of 0.85 (TA64). The markers TA5, TA14, TA18, TA21, TA64, TA71, TA106, TR20, TR26, TR58, TS43 were considered to be highly informative (PIC $\geq 0.8$ ), in evaluating allelic variation present in the chickpea accessions. Genetic diversity analysis resulted in the formation of two major clusters, using WARD's method of hierarchical clustering based on the dissimilarity index values. Cluster I represented a heterogeneous group with 42 genotypes representing no affiliation with the geographic regions and cluster II comprised of nine genotypes. Population structure based on allele frequency using Bayesian clustering approach identified discrete subpopulation which was similar to the dendrogram obtained using molecular data. Two groups were obtained $(K=2)$ with the mean $F_{S T}$ values of 0.3515 and 0.0972 respectively. However, four accessions were categorized as having admixed ancestry. The results revealed greater resolving power of SSR markers for chickpea germplasm. The availability of wide diversity in the germplasm could be effectively utilized in genetic resource conservation, association mapping as well as in breeding programmes for widening the genetic base of the cultivated chickpea. 
improvement programme (Allard, 1960). Diversity analysis is important because it directly alters the potential for genetic gain through selection (Kotal et al., 2010). It also assists the breeders to segregate the germplasm into heterotic groups to maximize the heterosis (Menz et al., 2004). Compared to morphological and biochemical markers, DNA markers are more reliable in revealing the genetic diversity existing in the germplasm collection. Molecular markers comprise of DNA sequences which can be used to identify/ generate unique tags to identify individuals in a germplasm and can give a precise resolution in assessing the diversity at gene level. They are highly polymorphic, reproducible, and are not influenced by the environment. Unlike morphological markers, these markers are not influenced by the plant ontogeny and can be analysed at different stages of plant growth. Further, these markers help in improving the efficiency of breeding program to severalfolds since selection is based not directly on the trait of interest but on the molecular marker tightly linked to the trait, thereby accelerating the generation of new varieties, especially for morphological traits which are difficult to be screened visually. Hence, in addition to the morphological marker based genetic diversity assessment in chickpea, the advent of DNA based marker technology has paved the way for assessing the molecular marker based genetic diversity prevalent in chickpea germplasm.

In chickpea, extraordinarily narrow genetic diversity was portrayed by commonly used biochemical and DNA-based markers, such as isozymes (Kazan and Muehlbauer 1991), restriction fragment length polymorphism (RFLP) and random amplified polymorphic DNA (RAPD), which all failed to reveal intraspecific variation (Simon and Muehlbauer 1997). But the microsatellite-fingerprinting proved that SSRs were abundant in chickpea genome and also effective in mining the genetic variation at intra-specific level (Sethy et al., 2006). The study of genetic diversity and structure helps in managing the gene banks, effective tagging of germplasm and it is a prerequisite in association mapping and can be used to avoid identifying false positive correlations between markers and traits (Pritchard et al., 2000). Hence this study was undertaken with the objective of assessing the genetic diversity and population structure in the chickpea germplasm.

\section{Materials and Methods}

The plant material for this study comprised of 51 chickpea accessions including genotypes with diverse origin obtained from ICRISAT, two nationally released varieties viz., Co 4, JAKI 9218 and a local land race from Thuraiyur (Table 1). DNA was extracted from the fresh young leaves of 51 genotypes following the high salt concentration method described by Angeles et al., (2005) with some modifications. The quality of DNA was checked in 0.8 per cent agarose gel electrophoresis. Fifty one chickpea germplasm accessions were subjected to microsatellite analysis. A total of 30 chickpea SSR primers (Winter et al., 1999) with known linkage groups and map positions were selected in order to have a random coverage of markers distributed throughout the 16 chromosomes of chickpea (Table 2). PCR reactions, were carried out in $20 \mu \mathrm{L}$ reactions containing 4.0 $\mu \mathrm{L}$ of genomic DNA $(10 \mathrm{ng} / \mu \mathrm{L}), 2.0 \mu \mathrm{L}$ of 10X Taq buffer containing $1.5 \mathrm{mM} \mathrm{MgCl}_{2}(20$ $\mathrm{mM}$ stock), $2.0 \mu \mathrm{L}$ of dNTP (2.5 mM of each dNTP), $1.0 \mu \mathrm{L}$ each of forward and reverse primer $(100 \mathrm{pmol} / \mu \mathrm{L}$ stock $), 0.5 \mu \mathrm{L}$ of Taq DNA Polymerase $(3 \mathrm{U} / \mu \mathrm{L})$ and $9.5 \mu \mathrm{L}$ of sterile water. PCR reaction cycles consisted of an initial denaturation step at $94^{\circ} \mathrm{C}$ for 5 minutes, followed by 35 cycles at $94^{\circ} \mathrm{C}$ for 30 s for denaturation, 30 seconds at an appropriate annealing temperature $\left(46^{\circ} \mathrm{C}\right.$ $54^{\circ} \mathrm{C}$ ) for primer annealing, and one minute at 
$72^{\circ} \mathrm{C}$ for extension. This was followed by a final extension step at $72^{\circ} \mathrm{C}$ for 10 minutes. The PCR products $(3 \mu \mathrm{L})$ were then run on a six per cent denaturing Poly Acrylamide Gel Electrophoresis (PAGE) at 150 volts for 1 hour and resolved by ethidium bromide staining procedure.

Polymorphism information content (PIC) or expected heterozygosity scores for each SSR marker was calculated based on the formula, $H j=1-\Sigma P i^{2}$. The binary marker data generated were subjected to Wards method (Ward, 1963) of hierarchical clustering using DARwin software version 6 (Perrier and Jacquemoud-Collet, 2006). The population structure was analyzed by employing a modelbased approach available in Structure 2.3.2 program (Pritchard et al., 2000) and the online version of Structure harvester (http://tayloro.biologyucla.edu/Struct_harvest) developed by Earl and vonHoldt (2012).

\section{Results and Discussion}

Understanding genetic relationship in germplasm collections are essential crop conservation and management strategies, for better utilization in breeding programmes. The exploration of the nature and structure of genetic diversity and relatedness among chickpea accessions provides an easy way for identification of new sources of germplasm harbouring valuable alleles for improving yield, grain quality and enhancing the level of resistance in cultivated varieties. To display the relatedness in the form of groups or clusters in the present study, the Ward's method of hierarchical clustering was employed, as it tends to form balanced clusters that could include the outlying accessions (Jobson, 1992).

Out of 30 SSR primers pairs, 28 primer pairs showed polymorphism (Plates 1-3). The 28 primer pairs detected a total of 217 alleles, with an average of 7.75 alleles per locus (Table 3) The number of alleles observed at each locus ranged from a minimum of six (TA28, TA80, TA89, TR1, TS12, TS45) to a maximum of twelve (TA71). The average PIC value was 0.75 and it ranged from a minimum of 0.53 (TA1) to a maximum of 0.85 (TA64). Out of the polymorphic 28 SSR primer pairs 11 primer pairs viz., TA64 (0.85), TA71 (0.84), TA106 (0.83), TA14 (0.83), TA5 (0.82), TA18 (0.82), TA21 (0.82), TR26 (0.82), TR20 (0.80), TR58 (0.80), TS43 (0.80) were highly informative and could be an effective and useful tool to determine the genetic differences among the chickpea accessions. The above results on polymorphism content revealed by SSR markers are consistent with other studies. For instance, Upadhyaya et al., (2008) using 48 SSR markers detected 1683 alleles in 2915 chickpea accessions. The alleles per locus ranged from 14 to 67 , which could be due to the large number of accessions surveyed. Saeed et al., (2011) using 19 SSR markers in 44 chickpea genotypes reported a total of 100 alleles with PIC values ranged from 0.44 for locus NCPGR7 to 0.84 for locus NCPGR6 and TA135 with a mean of 0.68 . The average number of allele per locus was 6.25 alleles and it ranged from two (locus NCPGR7) to 13 (TA135). Khamassi et al., (2012) using 16 SSR primer pairs reported that PIC values ranged from 0.593 (locus NCPGR4) to 0.898 (TA116) with an average of 0.72. Zaccardelli et al., (2013) identified 150 alleles ranging from two to 18 alleles per locus with an average of 9.4 alleles per locus using 16 SSR markers in 15 chickpea accessions. Ghaffari et al., (2014) using 14 SSR markers detected a total of 59 alleles in 60 accessions of chickpea with a mean of 4.2 alleles per locus and the PIC value ranged from 0.31 to 0.89 . De Giovann et al., (2017) reported 218 alleles using 22 SSR markers in 103 chickpea accessions. The number of alleles per locus ranged from a minimum of two (CaGMS-1235 
and NCPGR-76) to a maximum of 26 (CaGMS-13). A similar range of PIC values obtained in all these studies could also be attributed to a common source of SSR markers developed by Winter et al., (1999) which has been used in all these studies to assess the genetic diversity. However, Choudhary et al.,
(2012) reported a lower level of genetic diversity in chickpea germplasm with an average PIC value of 0.536 . This could be due to the analysis carried within the primary gene pool, comprising of genotypes which are more closely related to each other compared to the secondary and tertiary gene pool.

Fig.1 Dendrogram based on SSR marker data in chickpea germplasm

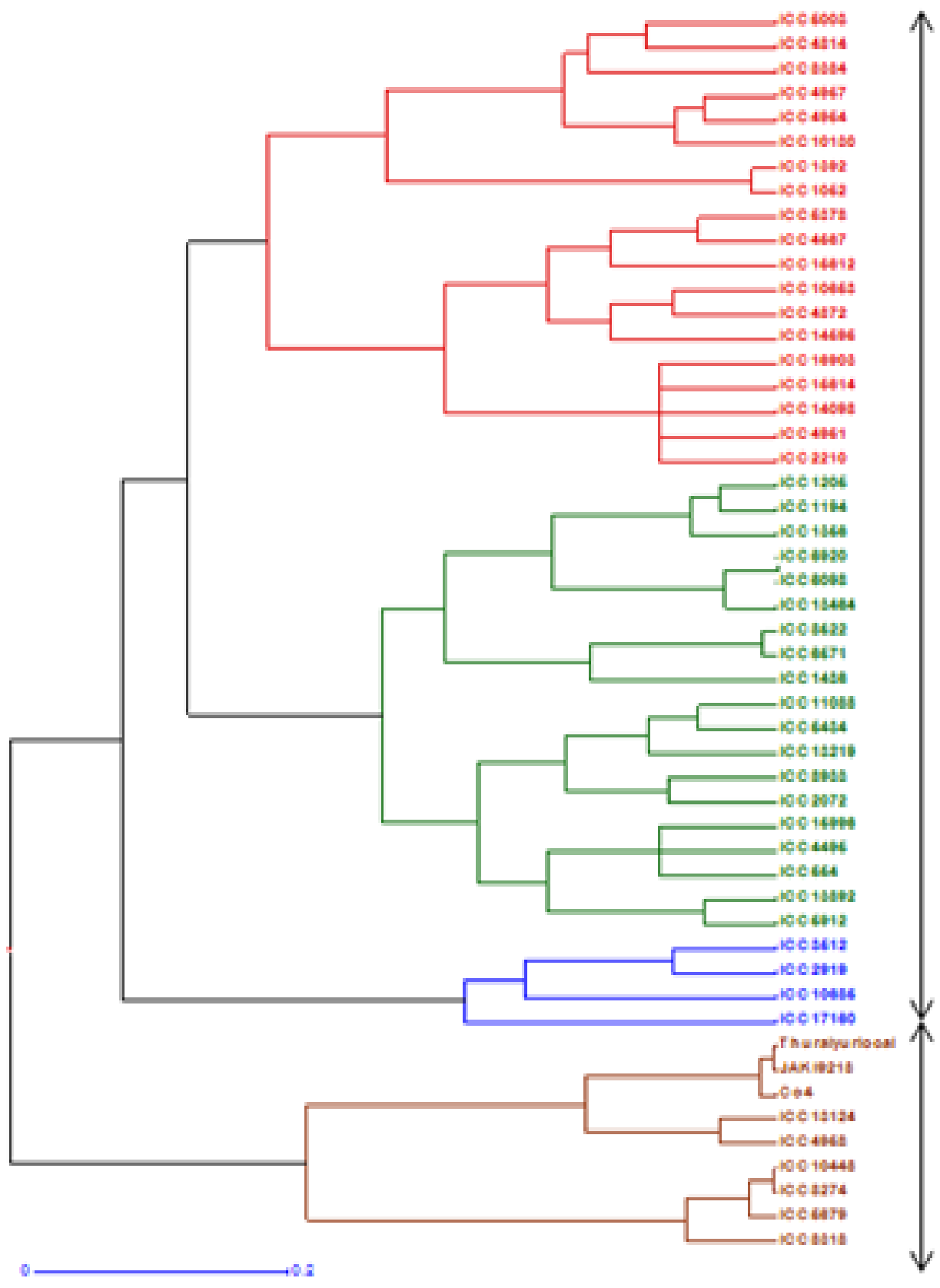

Cluster I

Cluster II 
Fig.2a Determination of number of population based on secondary statistics

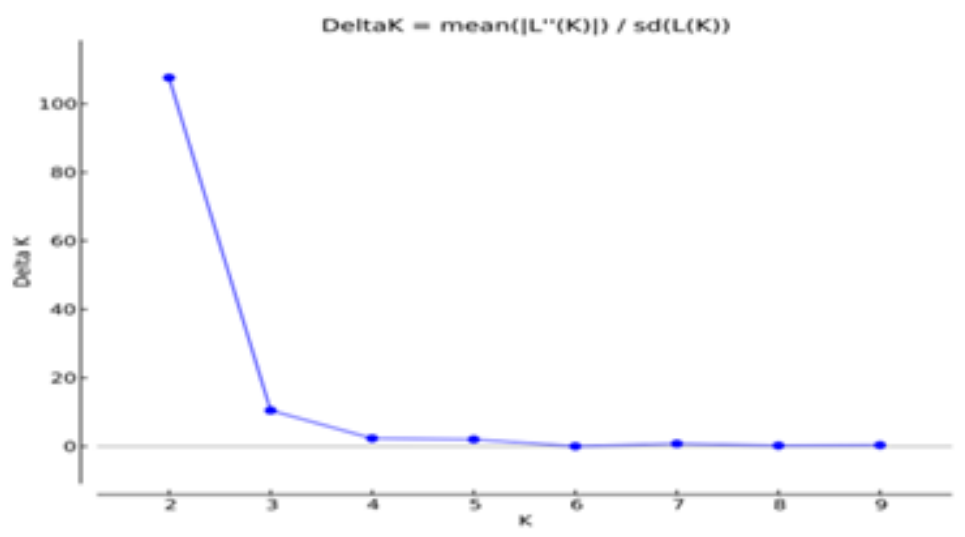

Fig.2b Population assignment for each accession at $\mathrm{K}=2$ based on STRUCTURE analysis

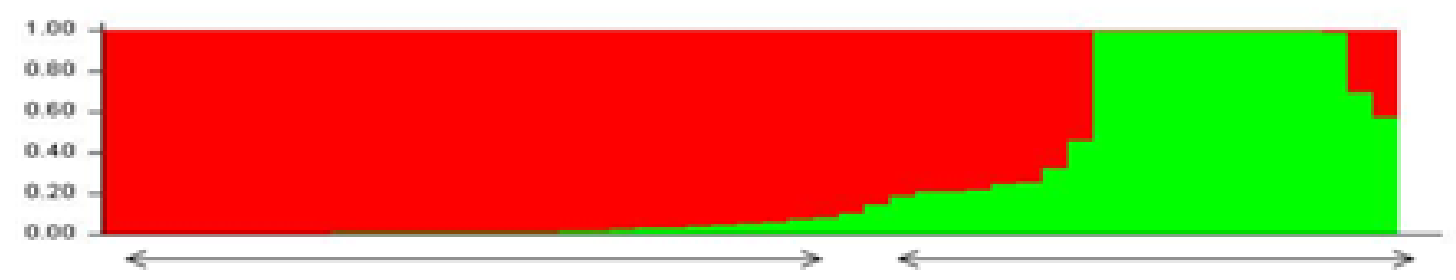

POPULATION 1

POPULATION 2

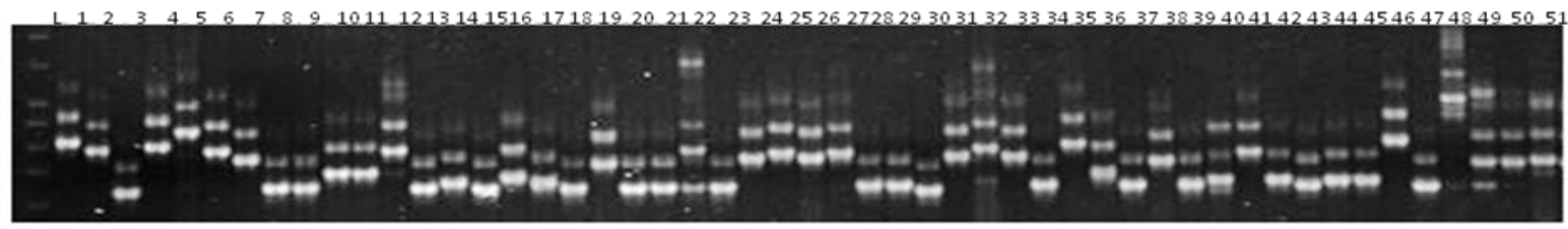

Plate 1 . SSR marker profile generated by the primer TA18

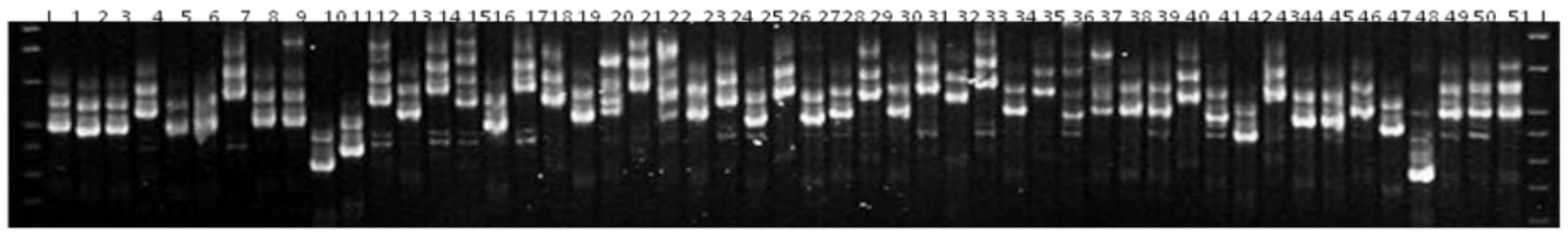

Plate 2 . SSR marker profile generated by the primer TA71

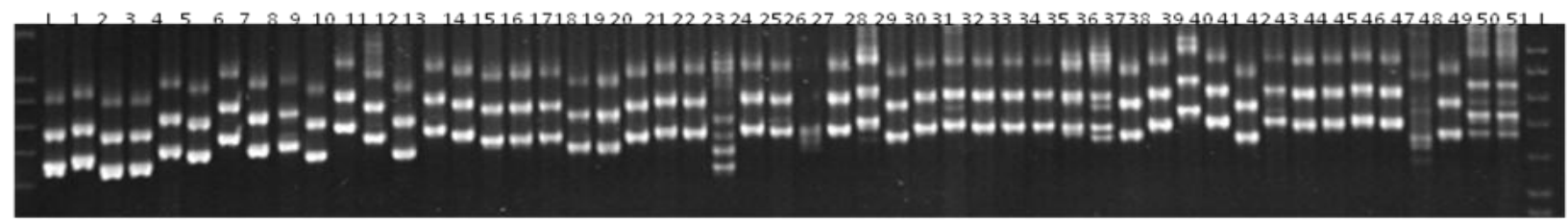

Plate 3 . SSR marker profile generated by the primer TS72 
Table.1 List of chickpea accessions, other names and their source of origin

\begin{tabular}{|c|c|c|c|}
\hline S. No. & Accessions/ Genotypes & Other names & Origin \\
\hline 1 & ICC 554 & $\mathrm{P} 436-2$ & India \\
\hline 2 & ICC 1052 & P 886, PI $217520-2$ & Pakistan \\
\hline 3 & ICC 1194 & P 1115 & India \\
\hline 4 & ICC 1205 & P 1120 & India \\
\hline 5 & ICC 1356 & P 1217 & India \\
\hline 6 & ICC 1392 & P 1240 & India \\
\hline 7 & ICC 1436 & P $1261-4$ & India \\
\hline 8 & ICC 2072 & P 1670, PB 22 & India \\
\hline 9 & ICC 2210 & P 1781, Algeria 444 & Algeria \\
\hline 10 & ICC 2919 & P 3318 - 1 & Iran \\
\hline 11 & ICC 3512 & P $4216-1$ & Iran \\
\hline 12 & ICC 4495 & P 6002 & Turkey \\
\hline 13 & ICC 4814 & P 6540 & Iran \\
\hline 14 & ICC 4567 & P $6112-2$ & India \\
\hline 15 & ICC 4872 & P $9667-1$ & India \\
\hline 16 & ICC 4951 & G 62 - 404, JG 62 & India \\
\hline 17 & ICC 4954 & P 9623; Mexican sel.2, H 208 & India \\
\hline 18 & ICC 4957 & Hima & India \\
\hline 19 & ICC 4958 & JGC 1 & India \\
\hline 20 & ICC 5003 & K 850 & India \\
\hline 21 & ICC 5378 & NP 56 & India \\
\hline 22 & ICC 5434 & Ponaflar 2 & India \\
\hline 23 & ICC 5679 & Annigeri 1 & India \\
\hline 24 & ICC 5912 & Т $39-1$ & India \\
\hline 25 & ICC 6098 & JG 74 & India \\
\hline 26 & ICC 6571 & P 542, PI 359366, NEC 647 & Iran \\
\hline 27 & ICC 6920 & P 4204, PI 360348, NEC 1154 & Iran \\
\hline 28 & ICC 8274 & Annigeri 1 & India \\
\hline 29 & ICC 8318 & Chandpur 2 & India \\
\hline 30 & ICC 8384 & PB $1-8$ & India \\
\hline 31 & ICC 8522 & JM 552 & Italy \\
\hline 32 & ICC 8933 & K 315, WR 315 & India \\
\hline 33 & ICC 10130 & CPS 1 & India \\
\hline 34 & ICC 10448 & RPSP 182 & India \\
\hline 35 & ICC 10653 & RS 11, SP 1 & India \\
\hline 36 & ICC 10685 & CRIC 34849 & Turkey \\
\hline 37 & ICC 11088 & BG 212, P340 x G 130 & India \\
\hline 38 & ICC 13124 & P 1390, PI 450831 & India \\
\hline 39 & ICC 13219 & P 3046, PI 450953, Ardabil 169 & Iran \\
\hline 40 & ICC 13892 & RAM $4-3$ & Ethiopia \\
\hline 41 & ICC 13464 & P 4204, PI 360348 & Turkey \\
\hline 42 & ICC 14098 & RBA 95 & Ethiopia \\
\hline 43 & ICC 14595 & RSW 1 & India \\
\hline 44 & ICC 15612 & AMF $237-1$ & Tanzania \\
\hline 45 & ICC 15614 & AMF $428-1$ & Tanzania \\
\hline 46 & ICC 15996 & ICCV 10/ICCL 83228, P 1231 x P 1265, Bharti & India \\
\hline 47 & ICC 16903 & KP 5388 & India \\
\hline 48 & ICC 17160 & ICCW 45, No. 205, ATC 42236, PI 489777 & Turkey \\
\hline 49 & Co 4 & - & India \\
\hline 50 & JAKI 9218 & - & India \\
\hline 51 & Thuraiyur local & - & India \\
\hline
\end{tabular}


Table.2 Details of SSR primer pairs used in the present study

\begin{tabular}{|c|c|c|c|c|c|c|}
\hline \multirow{2}{*}{$\begin{array}{l}\text { S. } \\
\text { No. }\end{array}$} & \multirow{2}{*}{$\begin{array}{l}\text { Primer } \\
\text { Name }\end{array}$} & \multicolumn{2}{|c|}{ Sequential Information (5' to $3^{\prime}$ ) } & \multirow{2}{*}{$\begin{array}{l}\mathrm{Tm} \\
\left({ }^{0} \mathrm{C}\right)\end{array}$} & \multirow{2}{*}{$\begin{array}{c}\text { Linkage } \\
\text { group }\end{array}$} & \multirow[t]{2}{*}{ References } \\
\hline & & Forward & Reverse & & & \\
\hline 1 & TA1 & TGAAATATGGAATGATTACTGAGTGAC & TATTGAAATAGGTCAGGCTTATAAAAA & 52 & LG 6 & Winter et al., (1999) \\
\hline 2 & TA5 & ATCATTTCAATTTCСТCAACTATGAAT & TCGTTAACACGTAATTTCAAGTAAAGAT & 50 & LG 3 & Winter et al., (1999) \\
\hline 3 & TA14 & TGACTTGCTATTTAGGGAACA & TGGCTAAAGACAATTAAAGTT & 47 & LG 4 & Winter et al., (1999) \\
\hline 4 & TA18 & AАAАТАATCТССАСТTСАСАAАТТTТС & ATAAGTGCGTTATTAGTTTGGTCTTGT & 51 & LG 5 & Winter et al., (1999) \\
\hline 5 & TA21 & GTACCTCGAAGATGTAGCCGATA & TTTTCCATTTAGAGTAGGATCTTCTTG & 54 & LG 5 & Winter et al., (1999) \\
\hline 6 & TA28 & TAATTGATCATACTCTCACTATCTGCC & TGGGAATGAATATATTTTTGAAGTAAA & 52 & LG 5 & Winter et al., (1999) \\
\hline 7 & TA37 & ACTTACATGAATTATCTTTCTTGGTCC & CGTATTCAAATAATCTTTCATCAGTCA & 50 & LG 7 & Winter et al., (1999) \\
\hline 8 & TA43 & GGTTGTGTTCTCCAGATTTT & AAGAGTTGTTGGAGAGCAA & 50 & LG 3 & Winter et al., (1999) \\
\hline 9 & TA45 & ATGCGTATAAAACCCAGAGA & TGTTTTTATTGGATTTTCAGTTTCA & 47 & LG 8 & $\begin{array}{c}\text { Winter et al., (1999), } \\
\text { Sabbavarapu et al., (2013) }\end{array}$ \\
\hline 10 & TA64 & ATATATCGTAACTCATTAATCATCCGC & AAATTGTTGTCATCAAATGGAAAATA & 51 & LG 1 & Winter et al., (1999) \\
\hline 11 & TA71 & CGATTTAACACAAAACACAAA & CCTATCCATTGTCATCTCGT & 46 & LG 3 & Winter et al., (1999) \\
\hline 12 & TA80 & CGAATTTTTACATCCGTAATG & AATCAATCCATTTTGCATTC & 47 & LG 4 & Winter et al., (1999) \\
\hline 13 & TA89 & ATCCTTCACGCTTATTTAGTTTTTACA & CAAGTAAAAGAGTCACTAGACCTCACA & 54 & LG 5 & $\begin{array}{l}\text { Winter et al., (1999), } \\
\text { Bharadwaj et al., (2011) }\end{array}$ \\
\hline 14 & TA106 & CGGATGGACTCAACTTTATC & TGTCTGCATGTTGATCTGTT & 47 & LG 4 & Winter et al., (1999) \\
\hline 15 & TA110 & ACACTATAGGTATAGGCATTTAGGCAA & TTCTTTATAAATATCAGACCGGAAAGA & 53 & LG 7 & Winter et al., (1999) \\
\hline 16 & TA125 & TTGAAATTGAACTGTAACAGAACATAAA & TAGATAGGTGATCACAAGAAGAGAATG & 50 & LG 1 & Winter et al., (1999) \\
\hline 17 & TA130 & TCTTTCTTTGCTTCCAATGT & GTAAATCCCACGAGAAATCAA & 47 & LG 2 & Winter et al., (1999) \\
\hline 18 & TA135 & TGGTTGGAAATTGATGTTTT & GTGGTGTGAGCATAATTCAA & 47 & LG 1 & Winter et al., (1999) \\
\hline 19 & TA180 & CATCGTGAATATTGAAGGGT & CGGTAAATAAGTTTCCCTCC & 47 & LG 5 & Winter et al., (1999) \\
\hline 20 & TR1 & CGTATGATTTTGCCGTCTAT & ACCTCAAGTTCTCCGAAAGT & 50 & LG 4 & Winter et al., (1999) \\
\hline 21 & TR19 & TCAGTATCACGTGTAATTCGT & CATGAACATCAAGTTCTCCA & 48 & LG 7 & Winter et al., (1999) \\
\hline 22 & TR20 & ACCTGCTTGTTTAGCACAAT & CCGCATAGCAATTTATCTTC & 50 & LG 2 & Winter et al., (1999) \\
\hline 23 & TR26 & TCATCGCAGATGATGTAGAA & TTGAACCTCAAGTTCTCTGG & 48 & LG 1 & Winter et al., (1999) \\
\hline 24 & TR29 & GCCCACTGAAAAATAAAAAG & ATTTGAACCTCAAGTTCTCG & 50 & LG 3 & Winter et al., (1999) \\
\hline 25 & TR58 & CTCTATATTTGTTTGTTTTTCGTTTTG & TAAAATGTGTAGGGTGCAGAATAAATA & 51 & LG 7 & Winter et al., (1999) \\
\hline 26 & TS12 & CTTAAATAATAAAATCCTAAATAAT & TAATCATATGAGAATCTTAGAATATCAC & 47 & LG 9 & Winter et al., (1999) \\
\hline 27 & TS43 & AAGTTTGGTCATAACACACATTCAATA & TAAATTCACAAACTCAATTTATTGGC & 51 & LG 3 & Winter et al., (1999) \\
\hline 28 & TS45 & TGACACAAAATTGTCTCTTGT & TGTTCTTAACGTAACTAACCTAA & 50 & LG 8 & Winter et al., (1999) \\
\hline 29 & TS72 & CAAACAATCACTAAAAGTATTTGCTCT & AAAAATTGATGGACAAGTGTTATTATG & 51 & LG 2 & Winter et al., (1999) \\
\hline 30 & TS83 & AAAAATCAGAGCCAACCAAAAA & AAGTAGGAGGCTAAATTATGGAAAAGT & 50 & LG 10 & Winter et al., (1999) \\
\hline
\end{tabular}


Int.J.Curr.Microbiol.App.Sci (2018) 7(2): 639-651

Table.3 Measures of genetic diversity based on SSR markers

\begin{tabular}{|c|c|c|c|}
\hline S. No. & SSR Locus & Total No. of alleles & PIC Value \\
\hline 1 & TA1 & 7 & 0.53 \\
\hline 2 & TA5 & 8 & 0.82 \\
\hline 3 & TA14 & 8 & 0.83 \\
\hline 4 & TA18 & 8 & 0.82 \\
\hline 5 & TA21 & 7 & 0.82 \\
\hline 6 & TA28 & 6 & 0.75 \\
\hline 7 & TA37 & 7 & 0.66 \\
\hline 8 & TA64 & 9 & 0.85 \\
\hline 9 & TA71 & 12 & 0.84 \\
\hline 10 & TA80 & 6 & 0.55 \\
\hline 11 & TA89 & 6 & 0.60 \\
\hline 12 & TA106 & 9 & 0.83 \\
\hline 13 & TA110 & 7 & 0.77 \\
\hline 14 & TA125 & 7 & 0.76 \\
\hline 15 & TA130 & 7 & 0.78 \\
\hline 16 & TA135 & 7 & 0.70 \\
\hline 17 & TA180 & 8 & 0.75 \\
\hline 18 & TR1 & 6 & 0.72 \\
\hline 19 & TR19 & 11 & 0.76 \\
\hline 20 & TR20 & 8 & 0.80 \\
\hline 21 & TR26 & 9 & 0.82 \\
\hline 22 & TR29 & 9 & 0.79 \\
\hline 23 & TR58 & 8 & 0.80 \\
\hline 24 & TS12 & 6 & 0.68 \\
\hline 25 & TS43 & 9 & 0.80 \\
\hline 26 & TS45 & 6 & 0.66 \\
\hline 27 & TS72 & 7 & 0.77 \\
\hline 28 & TS83 & 9 & 0.67 \\
\hline \multicolumn{2}{|r|}{ Total } & 217 & 20.93 \\
\hline \multicolumn{2}{|r|}{ Mean } & 7.75 & 0.75 \\
\hline
\end{tabular}


Table.4 Model based cluster membership coefficients of 51 chickpea accessions as determined by structure

\begin{tabular}{|c|c|c|c|c|}
\hline Accession & Origin & Q1 & Q2 & Population \\
\hline ICC 554 & India & 0.006 & 0.994 & P2 \\
\hline ICC 1052 & Pakistan & 0.013 & 0.987 & $\mathrm{P} 2$ \\
\hline ICC 1194 & India & 0.028 & 0.972 & $\mathrm{P} 2$ \\
\hline ICC 1205 & India & 0.118 & 0.882 & P2 \\
\hline ICC 1356 & India & 0.351 & 0.649 & Admixed \\
\hline ICC 1392 & India & 0.011 & 0.989 & P2 \\
\hline ICC 1436 & India & 0.007 & 0.993 & $\mathrm{P} 2$ \\
\hline ICC 2072 & India & 0.007 & 0.993 & $\mathrm{P} 2$ \\
\hline ICC 2210 & Algeria & 0.010 & 0.99 & $\mathrm{P} 2$ \\
\hline ICC 2919 & Iran & 0.009 & 0.991 & $\mathrm{P} 2$ \\
\hline ICC 3512 & Iran & 0.003 & 0.997 & $\mathrm{P} 2$ \\
\hline ICC 4495 & Turkey & 0.005 & 0.995 & $\mathrm{P} 2$ \\
\hline ICC 4814 & Iran & 0.010 & 0.99 & $\mathrm{P} 2$ \\
\hline ICC 4567 & India & 0.037 & 0.963 & $\mathrm{P} 2$ \\
\hline ICC 4872 & India & 0.993 & 0.007 & P1 \\
\hline ICC 4951 & India & 0.006 & 0.994 & $\mathrm{P} 2$ \\
\hline ICC 4954 & India & 0.005 & 0.995 & $\mathrm{P} 2$ \\
\hline ICC 4957 & India & 0.025 & 0.975 & $\mathrm{P} 2$ \\
\hline ICC 4958 & India & 0.997 & 0.003 & P1 \\
\hline ICC 5003 & India & 0.167 & 0.833 & $\mathrm{P} 2$ \\
\hline ICC 5378 & India & 0.182 & 0.818 & P2 \\
\hline ICC 5434 & India & 0.590 & 0.41 & Admixed \\
\hline ICC 5679 & India & 0.997 & 0.003 & P1 \\
\hline ICC 5912 & India & 0.240 & 0.76 & $\mathrm{P} 2$ \\
\hline ICC 6098 & India & 0.007 & 0.993 & $\mathrm{P} 2$ \\
\hline ICC 6571 & Iran & 0.009 & 0.991 & $\mathrm{P} 2$ \\
\hline ICC 6920 & Iran & 0.005 & 0.995 & $\mathrm{P} 2$ \\
\hline ICC 8274 & India & 0.997 & 0.003 & $\mathrm{P} 1$ \\
\hline ICC 8318 & India & 0.975 & 0.025 & P1 \\
\hline ICC 8384 & India & 0.029 & 0.971 & $\mathrm{P} 2$ \\
\hline ICC 8522 & Italy & 0.012 & 0.988 & $\mathrm{P} 2$ \\
\hline ICC 8933 & India & 0.049 & 0.951 & $\mathrm{P} 2$ \\
\hline ICC 10130 & India & 0.178 & 0.822 & $\mathrm{P} 2$ \\
\hline ICC 10448 & India & 0.997 & 0.003 & $\mathrm{P} 1$ \\
\hline ICC 10653 & India & 0.045 & 0.955 & $\mathrm{P} 2$ \\
\hline ICC 10685 & Turkey & 0.126 & 0.874 & $\mathrm{P} 2$ \\
\hline ICC 11088 & India & 0.117 & 0.883 & $\mathrm{P} 2$ \\
\hline ICC 13124 & India & 0.995 & 0.005 & $\mathrm{P} 1$ \\
\hline ICC 13219 & Iran & 0.114 & 0.886 & $\mathrm{P} 2$ \\
\hline ICC 13892 & Ethiopia & 0.032 & 0.968 & $\mathrm{P} 2$ \\
\hline ICC 13464 & Turkey & 0.004 & 0.996 & $\mathrm{P} 2$ \\
\hline ICC 14098 & Ethiopia & 0.003 & 0.997 & P2 \\
\hline ICC 14595 & India & 0.566 & 0.434 & Admixed \\
\hline ICC 15612 & Tanzania & 0.017 & 0.983 & P2 \\
\hline ICC 15614 & Tanzania & 0.009 & 0.991 & $\mathrm{P} 2$ \\
\hline ICC 15996 & India & 0.006 & 0.994 & P2 \\
\hline ICC 16903 & India & 0.295 & 0.705 & Admixed \\
\hline ICC 17160 & Turkey & 0.002 & 0.998 & P2 \\
\hline Co 4 & India & 0.996 & 0.004 & P1 \\
\hline JAKI 9218 & India & 0.995 & 0.005 & $\mathrm{P} 1$ \\
\hline Thuraiyur Local & India & 0.995 & 0.005 & P1 \\
\hline
\end{tabular}


SSR marker based cluster analysis using DARwin.6.0 program based on the dissimilarity index values divided the 51 chickpea accessions into two distinct groups (Figure 1). Cluster I represented a heterogeneous group with 42 genotypes representing different geographic regions. Cluster I was sub divided into three sub clusters, in which, sub cluster I and sub cluster II had 19 genotypes each and the sub cluster III had a minimum of four genotypes. Cluster II included nine genotypes, all belonging to India. This situation implies no parallelism between genetic diversity and geographical distribution. Similar trend was also reported by earlier workers in chickpea (Arora, 1990; Kumar and Arora, 1992). A lesser extent of relationship with geographical origin was also reported in lentil by Mekonnen et al., (2016). Similar findings from Murthy and Arunachalam (1996), suggested that the diversity can be obtained by genetic drift and selection in different environments rather than geographic distance. Further, dispersal of seed material and subsequent adaptation to various agro climatic conditions may also be responsible for such variation. Hence selection of genotypes for hybridization should be made only based on genetic diversity rather than geographical diversity. This is in concurrence with the findings of Bhattacharya and Ganguly (1998) and Harisatyanarayana and Reddy (2000). On contrary, Hajibarat et al., (2014) depicted a close relationship between genetic diversity and geographical origin.

A total of 30 SSR markers were used to understand the population structure in the panel of 51 accessions of chickpea employing a model-based approach of Structure. Fifty data sets were obtained by setting the number of possible clusters (K) from 1 to 10 with five replications each. The results were then permuted for each $\mathrm{K}$ value using CLUMPP software. The $\operatorname{LnP}(\mathrm{D})$ value for each given $\mathrm{K}$ increased with the increase of $\mathrm{K}$, but since there was no abrupt change in $\operatorname{LnP}(\mathrm{D})$, the probable $\mathrm{K}$ value could not be inferred. However, applying the second-order statistics $(\Delta \mathrm{K})$ developed by Evanno et al., (2005), there was a sharp peak of $\Delta \mathrm{K}$ at $\mathrm{K}=2$, suggesting two major populations (Fig. 2a). The values of membership coefficient for each genotype are presented in Table 4 . The genotypes were assigned to specific population group based on the threshold value of membership coefficients $(\geq 0.75)$. Out of fifty one genotypes, forty seven genotypes had the membership coefficients more than the threshold value of 0.75 and could be assigned unambiguously to either of the populations. However four genotypes showed admixtures. The STRUCTURE plot for $\mathrm{K}=2$ is presented in Figure 2b. The mean $F_{S T}$ values within the population 1 and 2 were 0.3515 and 0.0972 respectively. The $F_{S T}$ values are crucial, since population differentiation is relatively weaker if the $\mathrm{F}_{\mathrm{ST}}$ is less than 0.08, and determining the correct number of clusters becomes difficult irrespective of the methods used (Odong et al., 2011).

The present study revealed a structured population in chickpea, and was divided into two groups. The first group consisted of genotypes from different geographic regions where as the second group consisted of genotypes from India, which was similar to the dendrogram obtained by the WARD's method of hierarchical clustering based on molecular data. Population structure analysis by Keneni et al., (2011) revealed 5 clusters in the Ethiopian chickpea population comprising of 155 entries (139 Ethiopian germplasm accessions, eight nationally released varieties and eight breeding lines from ICARDA using 33 SSR primer pairs. The population structure indicated there existed relationship between geographical origins and genetic diversity. Teshome et al., (2012) also reported a 
structured population in chickpea with strong subpopulation fixation and differentiation indicating allele fixation in each subpopulation by analyzing a set of 999 chickpea accessions using SNP markers. Hajibarat et al., (2015) studied population structure of 48 chickpea genotypes comprising of 19 Iranian landrace and 29 international lines and cultivars using 38 SSR markers. This study also showed the presence of two distinct populations, one comprising of landraces and the other with cultivated types. This could be attributed to the introduction of exotic materials which could have broadened the genetic base of the chickpea.

While the level of genetic relatedness between the chickpea accessions provides scope for germplasm exploitation in breeding programmes because of its allelic richness, the presence of a structured population in chickpea as revealed by the present study, also indicates that care should be taken to utilize this information in forming core collections and in association mapping studies to avoid false positive associations.

\section{References}

Allard RW. 1960. Principles of Plant Breeding. John Wiley and Sons Inc., New York, 260.

Angeles, C., J. Gil, Laurena, C. Antonio, Tecson-Mendoza and E. Mae. 2005. Extraction of genomic DNA from the lipid, polysaccharide and polyphenolrich coconut (Cocos nucifera L.). Plant Molecular Biology Reporter, 23 (3): 297-298.

Arora, P.P. 1990. Divergence analysis in chickpea. Indian J. Pulses Res., 3: 11116.

Bharadwaj, C., S.K. Chauhan, S. Yadav, T. C. Satyavathi, R. Singh and J. Kumar. 2011. Molecular marker based linkage map of chickpea (Cicer arietinum L.) developed from desi $\times$ kabuli cross. Indian J. Agric. Sci., 81: 116-118.

Bhattacharya, A. and S.B. Ganguly. 1998. Genetic diversity in chickpea under normal and late seeding conditions. Legume Res., 21(3-4): 171-176.

Choudhary, P., S.M. Khanna, P.K. Jain, C. Bharadwaj, J. Kumar, P.C. Lakhera, R. Srinivasan. 2012. Genetic structure and diversity and analysis of the primary gene pool of chickpea using SSR makers. Genet. Mol. Res., 11(2): 891905.

De Giovanni, C., S. Pavan, F. Taranto, V. Di Rienzo, M.M. Miazzi, A.R. Marcotrigiano, G. Mangini, C. Montemurro, L. Ricciardi and C. Lotti. 2017. Genetic variation of a global germplasm collection of chickpea (Cicer arietinum L.) including Italian accessions at risk of genetic erosion. Physiology and Molecular Biology of Plants, 23(1): 197-205.

Earl, D. A. and vonHoldt. 2012. STRUCTURE HARVESTER: a website and program for visualizing STRUCTURE output and implementing the Evanno method. Conservation Genetics Resources, 4(2): 359-361.

Evanno, G., S. Regnaut and J. Goudet. 2005. Detecting the number of clusters of individuals using the software STRUCTURE: a simulation study. Molecular Ecology, 14: 2611-2620.

Ghaffari, P., R. Talebi and F. Keshavarzi. 2014. Genetic diversity and geographical differentiation of Iranian landrace, cultivars, and exotic chickpea lines as revealed by morphological and microsatellite markers. Physiology and Molecular Biology of Plants, 20(2):225233.

Hajibarat, Z., A. Saidi, Z. Hajibarat and R. Talebi. 2014. Genetic diversity and population structure analysis of landrace and improved chickpea (Cicer 
arietinum) genotypes using morphological and microsatellite markers. Environmental and Experimental Biology, 12: 161-166.

Hajibarat, Z., A. Saidi, Z. Hajibarat and R. Talebi. 2015. Characterization of genetic diversity in chickpea using SSR markers, Start Codon Targeted Polymorphism (SCoT) and Conserved DNA-Derived Polymorphism (CDDP). Physiology and Molecular Biology of Plants, 21(3):365-373.

Harisatyanarayana, N. and N.S. Reddy. 2000. Genetic divergence in chickpea. J. Res. Angrau., 29: 31-33.

Jobson, J.D. 1992. Applied Multivariate Data Analysis, II, Springer, New York.

Kazan, K. and F.J. Muehlbauer. 1991. Allozyme variation and phylogeny in annual species of Cicer (Leguminosae), Plant Syst. Evol., 175: 11.

Keneni, G., E. Bekele, M. Imtiaz, K. Dagne, E. Getu and F. Assefa. 2011. Genetic diversity and population structure of Ethiopian chickpea (Cicer arietinum L.) germplasm accessions from different geographical origins as revealed by microsatellite markers. Plant Molecular Biology Reporter, 30(3):654-665.

Khamassi, K., L.B. Ben Kaab, S. Khoufi, R. Chaabane, J.A.T. Da Silva, I.J. Mackay and M.B. Naceur. 2012. Morphological and molecular diversity of Tunisian chickpea. European Journal of Horticultural Science, 31-40.

Kotal, B.D., A. Das and B.K. Choudry. 2010. Genetic variability and association of characters in wheat (Triticum aestivum L.). Asian J. Crop Sci., 2: 155-160.

Kumar, L. and P.P. Arora. 1992. Multivariate analyses in chickpea. Indian Journal of Pulses Research, 5: 1-5.

Mekonnen, F., F. Mekbib, S. Kumar, S. Ahmed and T.R. Sharma. 2016. Molecular diversity and population structure of the Ethiopian lentil (Lens
Culinaris Medikus) genotype assessment using SSR markers. Journal of Crop Science and Biotechnology, 19(1): 1-11.

Menz, M.A., R.R. Klein, N.C. Unruh, W.L. Rooney, P.E. Klein and J.E. Mullet. 2004. Genetic diversity of public inbreds of sorghum determined by mapped AFLP and SSR markers. Crop Sci., 44: 1236-1244

Murty, B.R. and V. Arunachalam, 1966. The nature of genetic divergence in relation to breeding system in crop plants. Indian J. Genet., 26: 188-198.

Odong, T. L., J. Van Heerwaarden, J. Jansen, T. J. L. Van Hintum and F. A. Van Eeuwijk. 2011. Determination of genetic structure of germplasm collections: are traditional hierarchical clustering methods appropriate for molecular marker data? Theor. Appl. Genet., 123: 195-205.

Perrier, X. and J.P. Jacquemoud-Collet. 2006. DARwin software. Available at http://darwin.cirad.fr/darwin. (The weighted pair group method with arithmetic mean dendrogram was produced using the DARwin software (Perrier and Jacquemoud-Collet 2006)).

Pritchard, J.K., M. Stephens, N.A. Rosenberg and P. Donelly. 2000. Association mapping in structured populations. Am. J. Hum. Genet, 37: 170-181.

Sabbavarapu, M.M., M. Sharma, S.K. Chamarthi, N. Swapna, A. Rathore, M. Thudi, P.M. Gaur, S. Pande, S. Singh, L. Kaur and R.K. Varshney. 2013. Molecular mapping of QTLs for resistance to Fusarium wilt (race 1) and Ascochyta blight in chickpea (Cicer arietinum L.). Euphytica, 193(1): 121133.

Saeed, A., H. Hovsepyan, R. Darvishzadeh, M. Imtiaz, S.K. Panguluri and R. Nazaryan. 2011. Genetic diversity of Iranian accessions, improved lines of 
chickpea (Cicer arietinum L.) and their wild relatives by using simple sequence repeats. Plant Molecular Biology Reporter, 29(4):848-858.

Sethy, N.K., B. Shokeen, K.J. Edwards and S. Bhtia. 2006. Development of microsatellite markers and analysis of intra-specific genetic variability in chickpea (Cicer arietinum L.). Theoretical and Applied Genetics, 112: 1416-1428.

Simon, C.J. and F.J. Muehlbauer. 1997. Construction of a chickpea linkage map and its comparison with maps of pea and lentil. J. Hered., 88: 115-119.

Teshome, K., F. Mekbib, S. Ahmed, Pooran, M. Gaur, K. Varshney and Rajeev. 2012. Genetic diversity, Population Structure, Association Mapping and Development of Core Collection in Ethiopian Chickpea (Cicer arietinum L.) Germplasm. Electronic thesis. Haramaya University Institutional Repository.

Upadhyaya, H.D., S.L. Dwivedi, M. Baum, R.K. Varshney, S.M. Udupa, C.L.L.
Gowda, D. Hoisington and S. Singh 2008. Genetic structure, diversity and allelic richness in composite collection and reference set of chickpea (Cicer arietinum L.). BMC Pl. Biol., 8:106.

Vavilov, N. I. 1926. Studies on the origin of cultivated plants. Leningrad, 129-238.

Ward, J.H. 1963. Hierarchical groupings to optimize an objective function. $J$. Am. Stat. Assoc., 58: 236-244.

Winter, P., T. Pfaff, S.M. Udupa, B. Huttel, P.C. Sharma, S. Sahi, R. ArrequinEspinoza, F. Weigand, F.J. Muehlbauer and G. Kahl. 1999. Characterization and mapping of sequence-tagged microsatellite sites in the chickpea $(C$. arietinum L.). Mol. Gen. Genet., 262: $90-101$.

Zaccardelli, M., G. Sonnante, F. Lupo, A.R. Piergiovanni, G. Laghetti, F. Sparvoli and L. Lioi. 2013. Characterization of Italian chickpea (Cicer arietinum L.) germplasm by multidisciplinary approach. Genetic Resources and Crop Evolution, 60(3):865-877.

\section{How to cite this article:}

Samyuktha, S.M., J.R. Kannan Bapu and Geethanjali, S. 2018. Molecular Genetic Diversity and Population Structure Analysis in Chickpea (Cicer arietinum L.) Germplasm using SSR Markers. Int.J.Curr.Microbiol.App.Sci. 7(02): 639-651. doi: https://doi.org/10.20546/ijcmas.2018.702.079 